\title{
Effects of local non-equilibrium in rapid eutectic solidification. Part 2: modeling versus experimental data
}

\author{
Junfeng $\mathrm{Xu}^{1}$ and Peter Galenko ${ }^{2}$ \\ ${ }^{1}$ Friedrich Schiller Universität Jena Physikalisch-Astronomische Fakultät \\ ${ }^{2}$ Friedrich-Schiller-Universitat Jena
}

July 18, 2020

\begin{abstract}
The developed model of diffusion-limited and diffusionless solidification of eutectic alloy describes the relation "undercooling $(\Delta \mathrm{T})$-velocity $(\mathrm{V})$-interlamellar spacing $(\lambda)$ " for two cases. Namely, if the lamellar velocity V is smaller than the solute diffusion speed in bulk liquid VD, VVD, the solidification is mainly controlled by kinetic and thermal undercoolings. We show an influence of model parameters on the growth kinetics of eutectic solidification. Comparison of the model predictions with experimental data obtained on Fe-B samples processed in melt-glass fluxing is given.
\end{abstract}

\section{Hosted file}

Part 2 2020_07_13.doc available at https://authorea.com/users/343920/articles/470544effects-of-local-non-equilibrium-in-rapid-eutectic-solidification-part-2-modelingversus-experimental-data

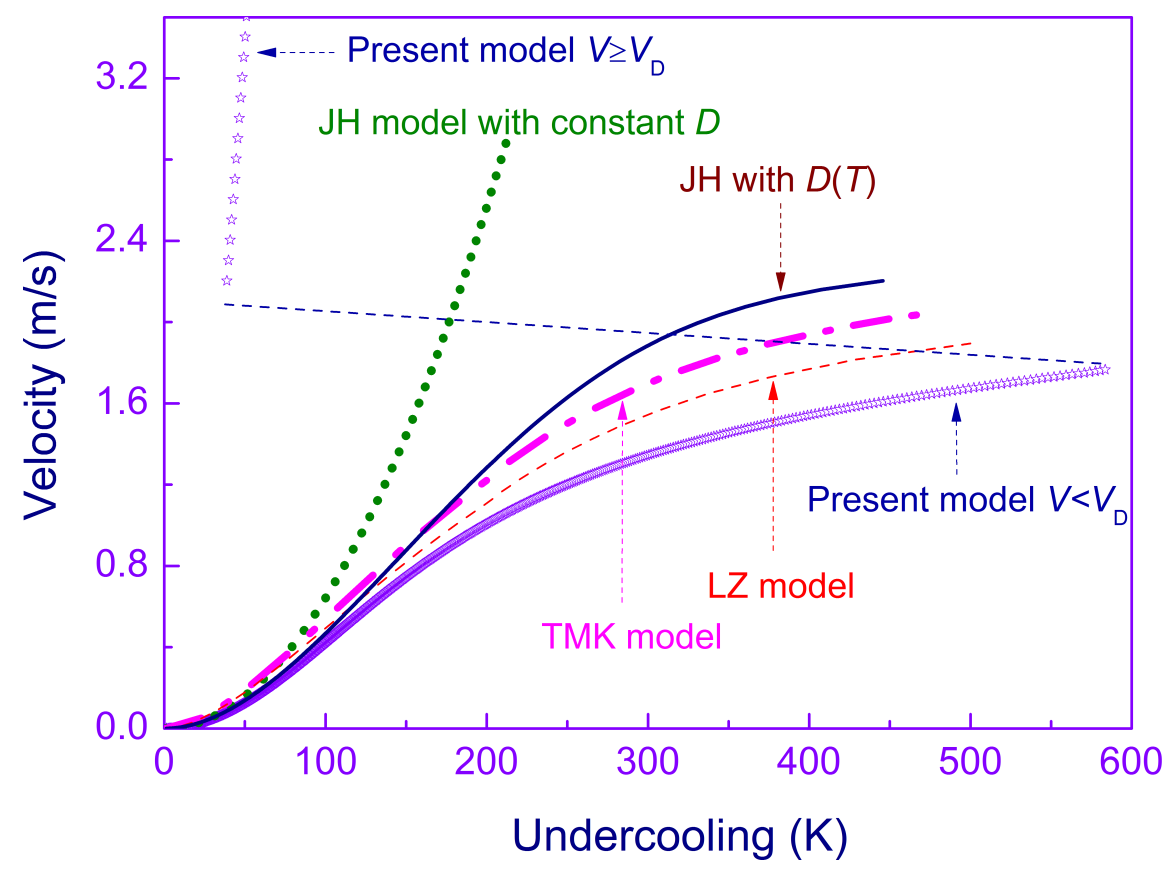





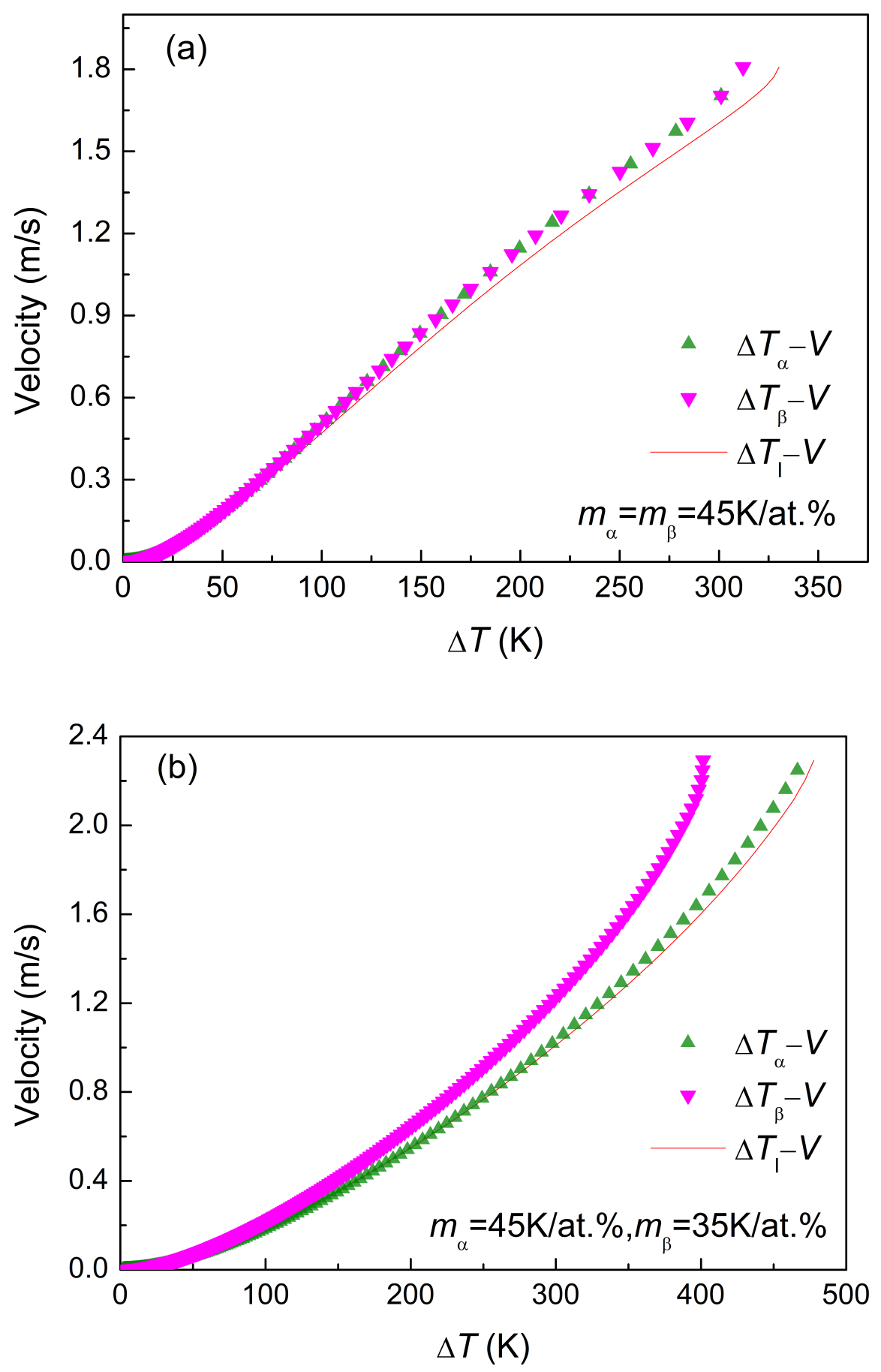

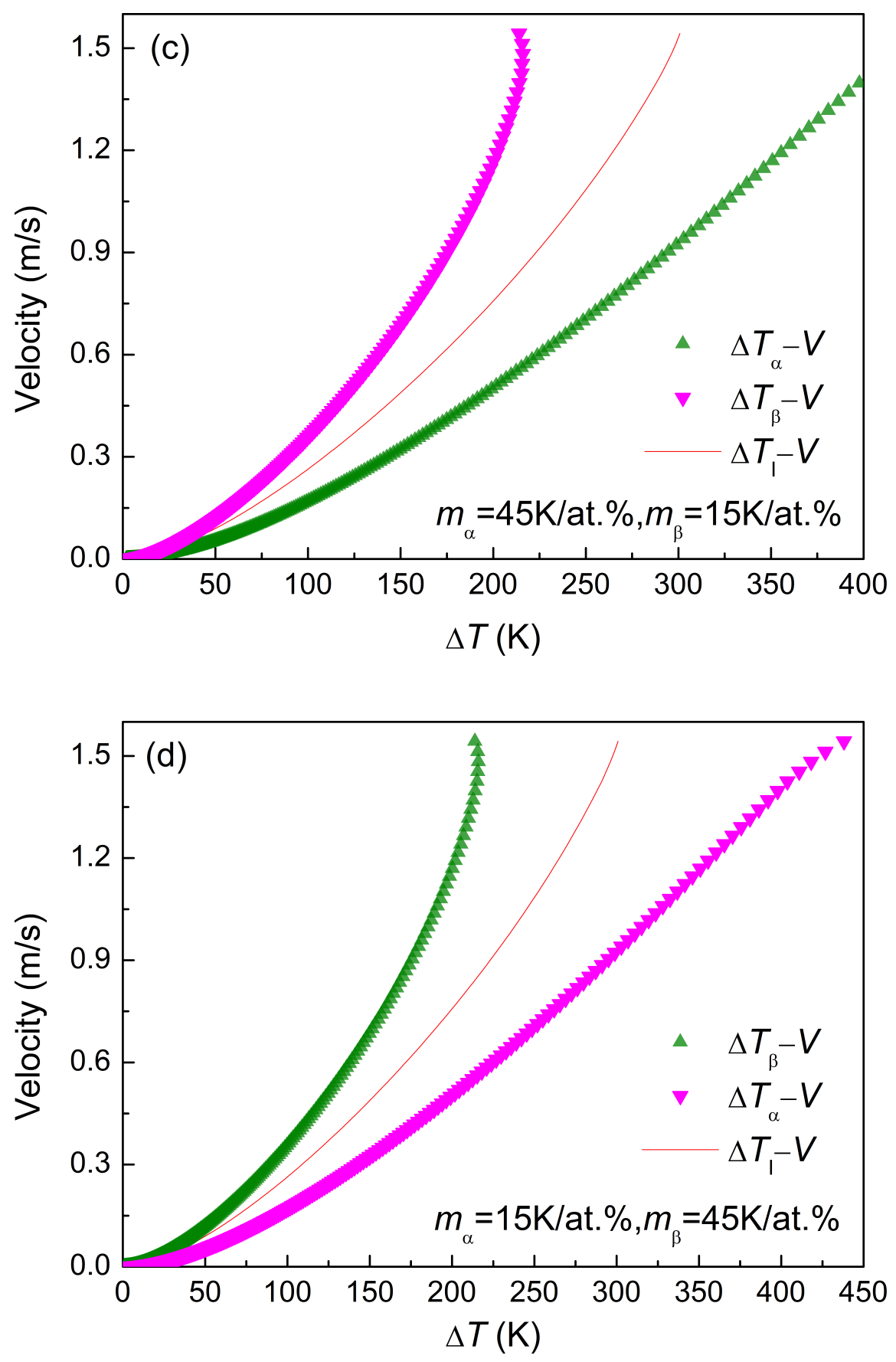

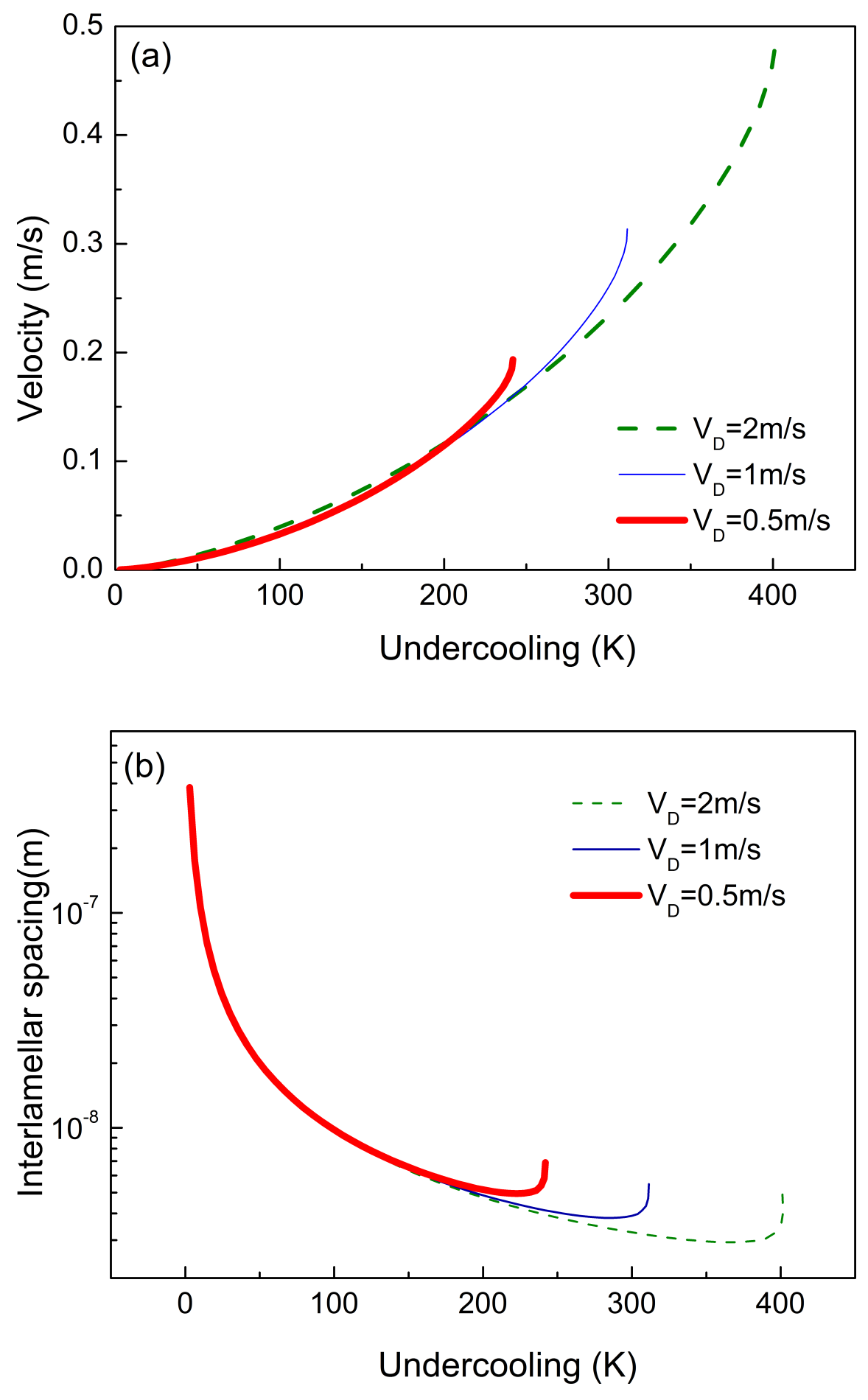

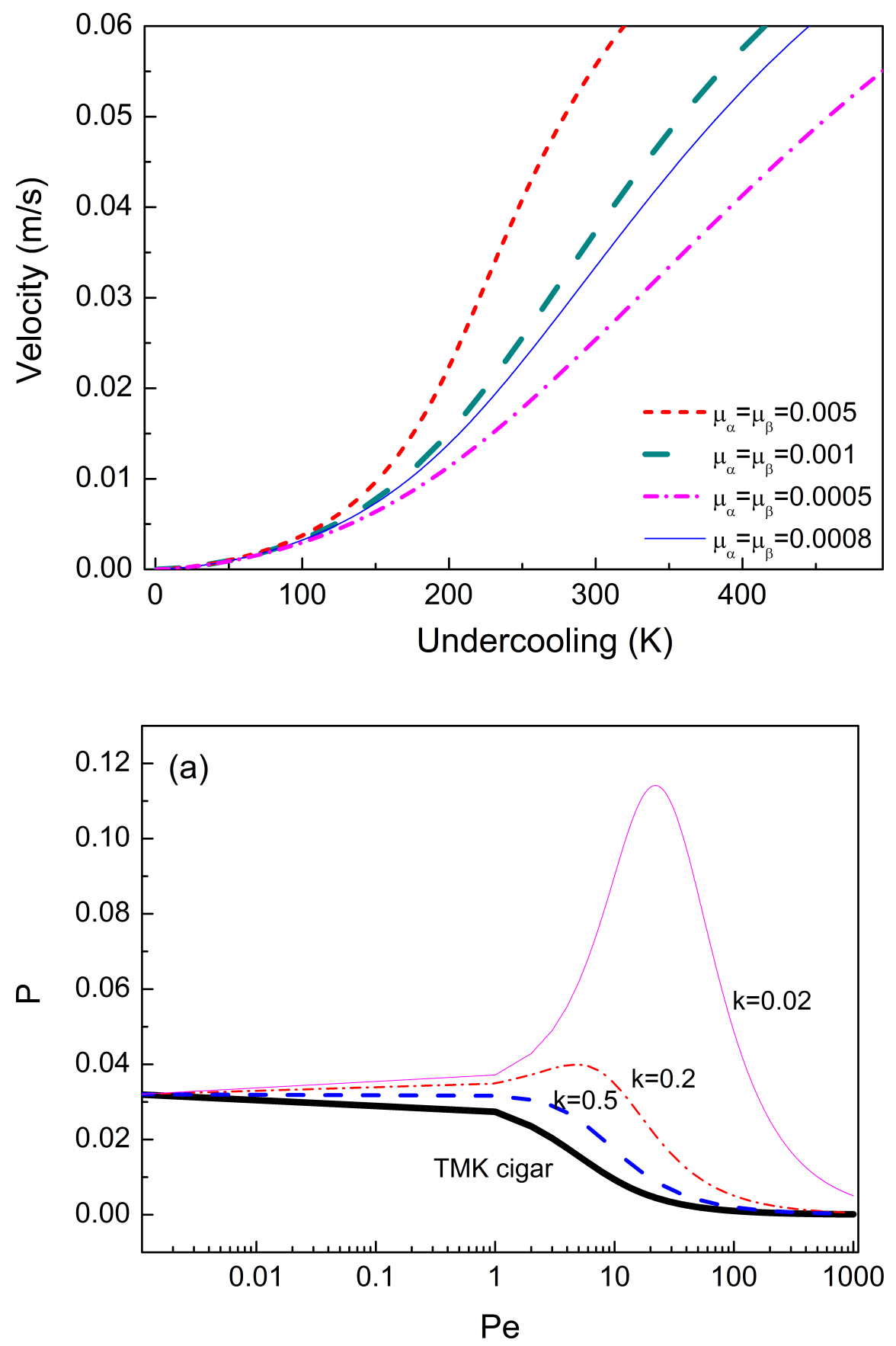

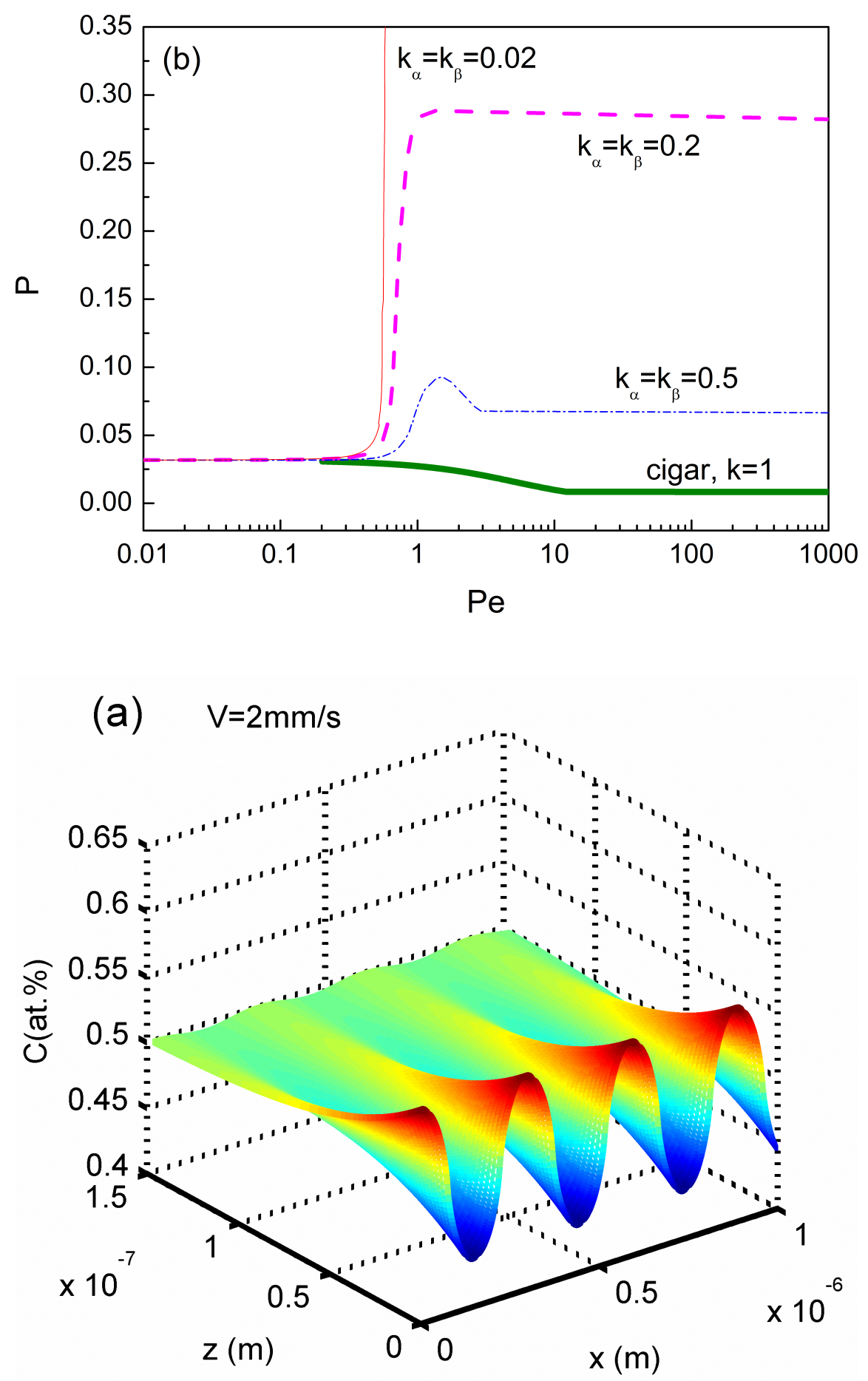
(b) $\quad \mathrm{V}=6 \mathrm{~mm} / \mathrm{s}$
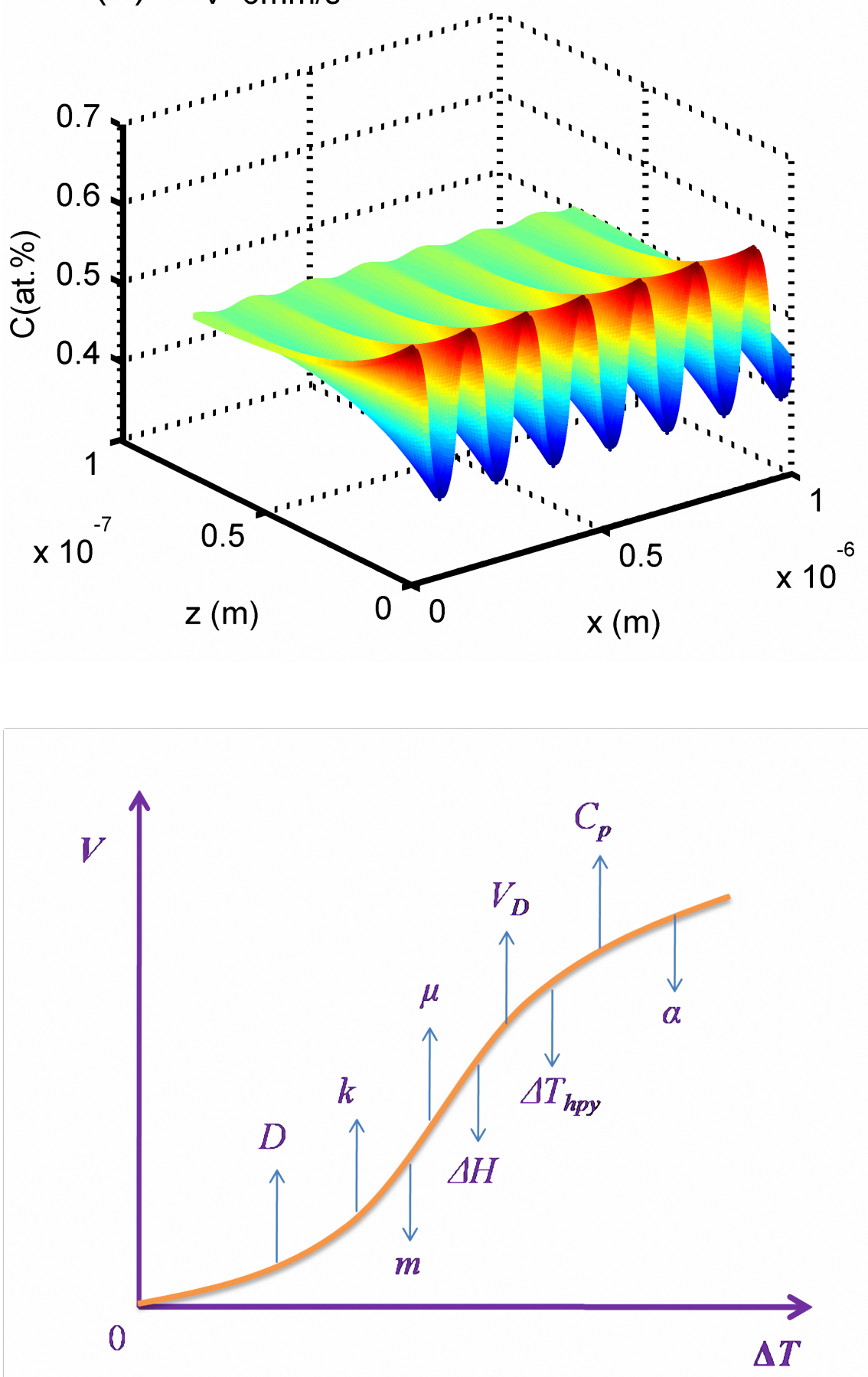

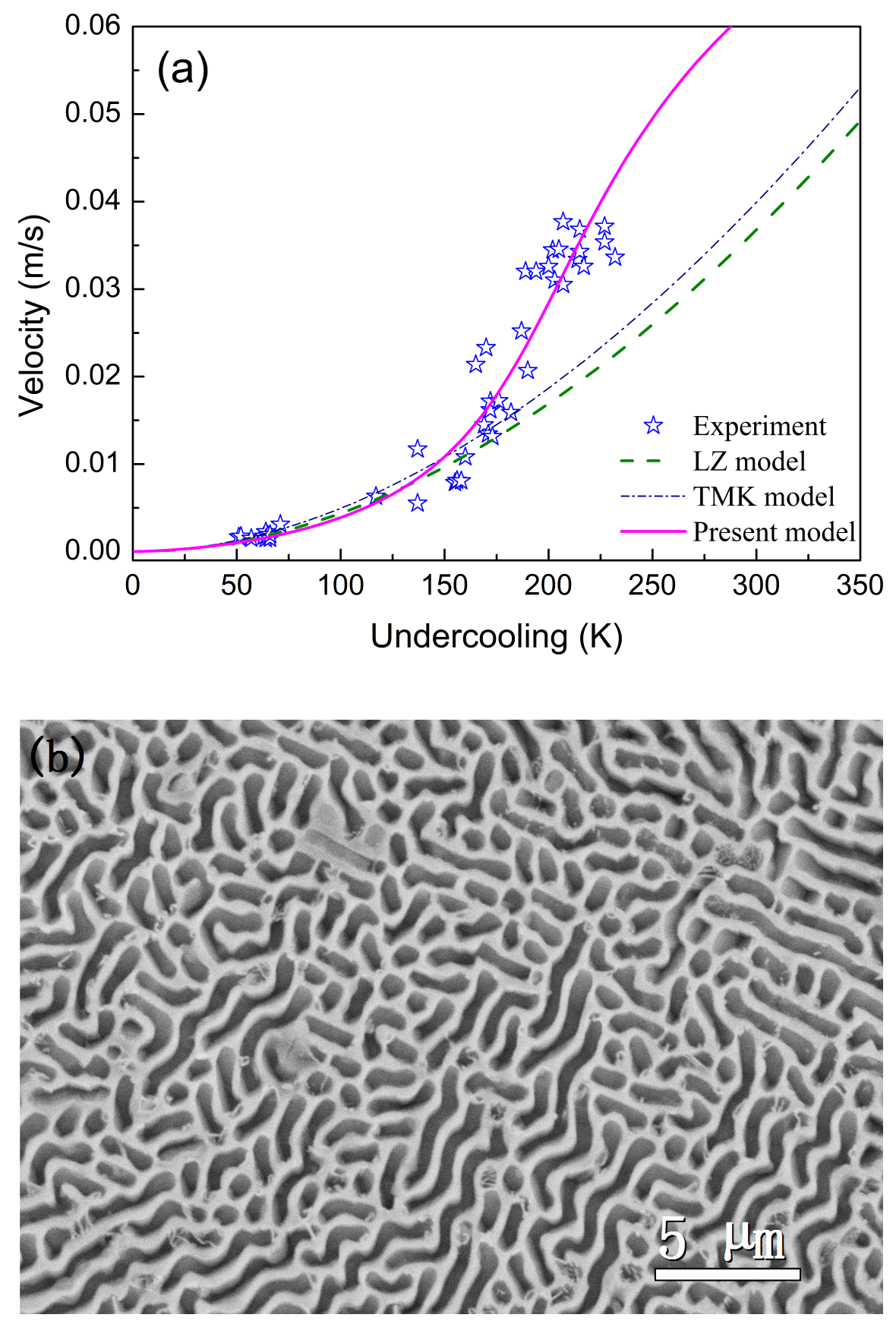

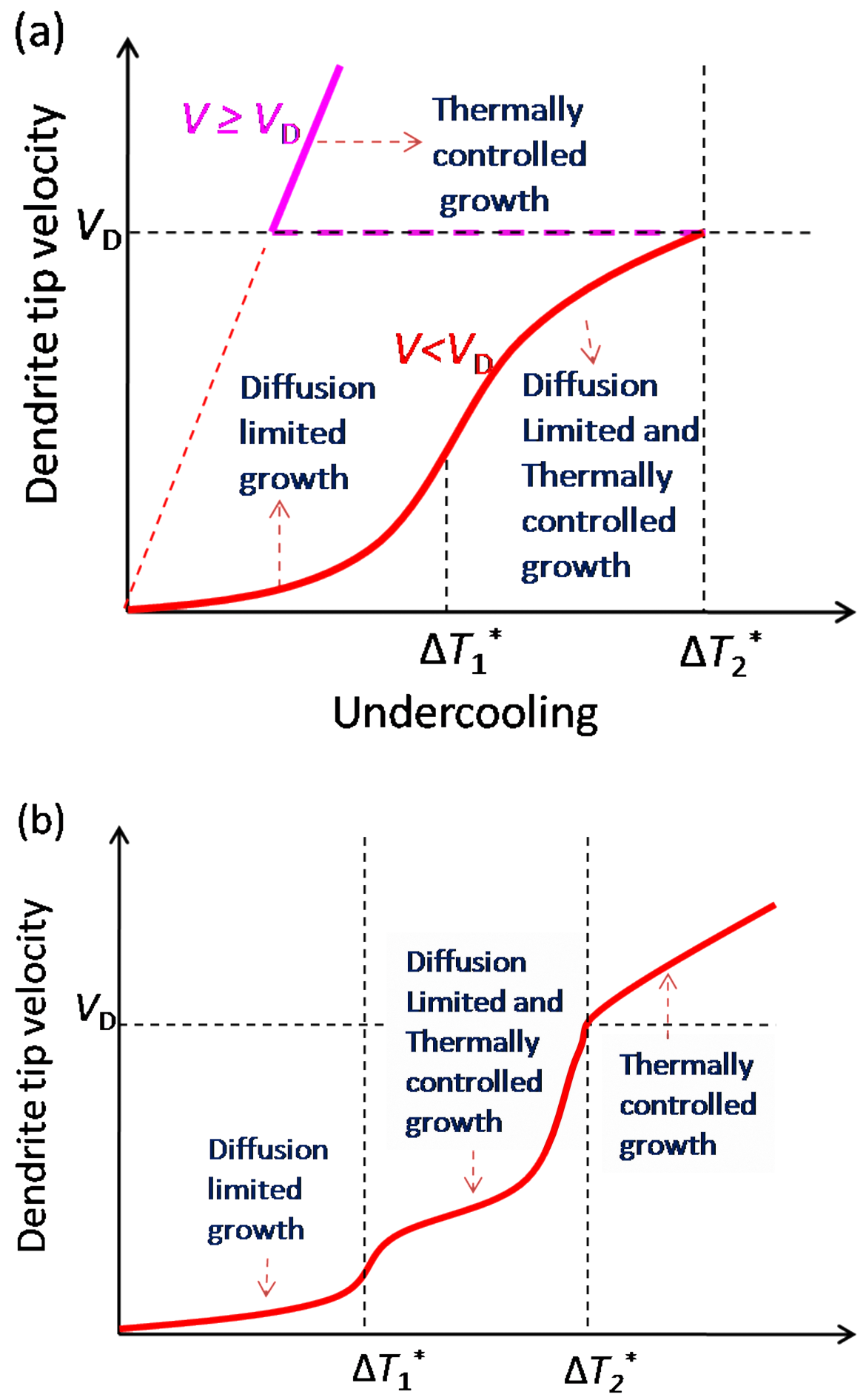

Undercooling 